\title{
Perceptions of Motherhood: Differences among Racial Majority and Minority Women
}

\author{
Ekeoma E. Uzogara
}

\begin{abstract}
Perceptions and experiences of motherhood are important dimensions of women's lives. However, research has often overlooked the significance of social contexts (e.g. racial minority status or socioeconomic inequality) in how women interpret their experiences as mothers and emotional consequences of not meeting societal expectations of "intensive mothering." This article compared American racial minority (Nonwhites) and majority groups' (Whites) appraisals of their effectiveness as mothers, feelings of guilt and worry, and perceptions of whether they outperformed their own mothers' parenting skills. Using a national survey sample of 581 American mothers (ages 18-68), findings indicated that there were advantages and disadvantages for Whites and Nonwhites. White mothers reported closer relationships with their own mothers and were more apt to emulate her parenting style; however, Nonwhites were more confident in their parenting abilities, expressed less worry and guilt overall, but specifically felt more guilty than Whites about financial obstacles to parenting. Implications of results suggest that Whites - a class-privileged group - may lack some cultural or psychological resources that Nonwhites possess to buffer some of the stress of motherhood.
\end{abstract}

Index Terms-Intergenerational mothering processes, intersectionality, maternal guilt and worry, race.

\section{INTRODUCTION}

Most American women become mothers during their lives [1] and motherhood has historically been a distinguishing characteristic of womanhood. Research also suggested that many women consider their roles as mothers as a more central part of their identity than their careers and marital status [2], [3]. Hays' [4] pioneering work on the social construction of motherhood (i.e. "intensive mothering") indicated that societies perceived women as the ideal, central caregivers who must sacrifice their own interests and needs to fully devote their time to domestic aspirations; in essence, "ideal" mothers are expected to function as conduits through which family members' needs are fulfilled, preferably as stay-at-home mothers. Although motherhood can be a source of fulfillment for women, attempting to measure up to society's stereotypical expectations of a "good mother" can lead to guilty, worry, stress, compromised mental health and feelings of inadequacy in women [4]-[8].

It is important to consider contemporary American women's experiences and perceptions of motherhood within social contexts. The literature on motherhood has largely examined experiences of White middle class mothers and

Manuscript received February 15, 2015; revised May 10, 2015.

Ekeoma E. Uzogara is with the Center for the Education of Women, University of Michigan, Ann Arbor, MI 48104, USA (e-mail: ekeoma@umich.edu). often overlooked the impact of intersecting structures of social class, racial minority status, and sexual orientation. It is well known that Nonwhite women (e.g. African American, Latina, Native American and Asian American) are less privileged than White (Caucasian) women in accumulated socioeconomic resources, poverty rates, marriage rates, and their options to forgo paid employment to be stay-at-home mothers [9] - important factors that contribute to chronic stress for mothers [10]. However, since Nonwhites and disadvantaged groups psychologically protect themselves by socially comparing their life circumstances to peers of the same race or social status [11], White and Nonwhite mothers may not necessarily differ in their (subjective) self-appraisals of their effectiveness as mothers. Thus, it is hypothesized that:

$\mathbf{H}_{1 \mathbf{a}}$ : White and Nonwhite mothers will not differ in how they assess their effectiveness as parents.

Furthermore, some research has suggested that, culturally, Nonwhite ethnic groups have more interdependent/collectivistic relationships with members of their extended families and communities [8]. This is relevant because collectivistic worldviews may contribute to how women interpret their roles as mothers and may influence whether certain life circumstances even trigger guilt or worry. For example, Nonwhite mothers may not feel as guilty as Whites for working outside of the home or spending time away from their children because financially providing for their family is often an important source of pride or accomplishment for mothers in their disadvantaged communities [8]-[10] since Nonwhites are more likely to be unmarried (single) mothers. However, Nonwhites may feel more guilt for not having adequate resources or money to meet their children's basic needs. Because of structural racism that has occurred in the United States historically, Nonwhite mothers typically juggled a "double shift" of domestic work and paid labor. In contrast, White mothers, historically, were married and had the option to be stay-at-home mothers and fully devote their time to an "intensive mothering" style [4]. It is plausible that contemporary White mothers may feel more guilt for spending time away from their children if they consider their mothers' choices to be stay-at-home mothers (e.g. during the 1950-60s) as an ideal standard of parenting.

$\mathbf{H}_{1 \mathbf{b}}$ : White and Nonwhites will differ in their reports of worry, guilt and sources of guilt

Other important factors that may shape women's perceptions of motherhood are intergenerational processes within their families of origin. Women may reflect on their mothers' parenting styles as a standard of reference when they evaluate their own effectiveness and roles as mothers [2]. Furthermore, since Nonwhites are more likely to have 
collectivistic/interdependent relationships [8] within their families while Whites have more individualistic cultures, their respective perceptions of closeness to their mothers may differ. Moreover, since collectivistic cultures value intergenerational relationships and promote obedience or deference to elder parents [12], Nonwhite adult mothers may perceive their relationships with their aging mothers as a traditional parent-child (hierarchical) connection while White adult mothers may consider their mothers to be their friends (egalitarian). Research also suggests that people learn values from parents and repeat relationship patterns observed within their families [9]; thus, it is plausible that women that had secure, satisfying relationships with their mothers will develop more fulfilling relationships with their own children. Thus, it is hypothesized that:

$\mathbf{H}_{2 \mathbf{a}}$ : Whites and Nonwhites will differ in their self-reported closeness to their mothers.

$\mathbf{H}_{\mathbf{2 b}}$ : Women that report closer relationships with their mothers during their youth (past) will also report more satisfying relationships with their own children (present).

A gap in this literature is research that addresses whether contemporary White and Nonwhite women differ in how they emulate their mothers' parenting styles. Some qualitative studies of women born after 1965 have indicated that Nonwhites challenge traditional "intensive mothering" ideologies that require mothers to be the primary caregivers [13]; for example, some ethnic minorities engage in "other-mothering" that encourages relatives and community members to participate in caring for their children [10]. Further, the historical context of the lives of women of color is also important to consider since there has been significant shifts in attitudes about raising children outside of marriage, perceptions of the traditional family ideal, cohabitation, and women's employment in addition to broader societal changes after the Civil Rights Movement [14], [15]. It is likely that these minority groups that have been historically marginalized had to adopt new mothering strategies during the 21 st century that significantly deviated from their mothers' styles during the 1950s-1970s; thus, Nonwhites may not emulate their mothers as much as Whites, and Nonwhites may not perceive that their mothers were more effective parents than they are:

$\mathbf{H}_{2 \mathbf{c}}$ : Whites will be more likely to emulate their mothers' parenting style.

\section{METHOD}

The analyses in this paper used the ABC News/Good Housekeeping Mother's Day Poll [16] collected in 2006. Using random-digit dialing procedures of listed and unlisted phone numbers, interviewers called homes across the United States and spoke with mothers that had at least one child (biological or adopted) under the age of 18 living in her home. The sample was statistically weighted using demographic information from United States Census data to account for differing probabilities of selection of respondents. Additional information about the survey is available here: http://www.icpsr.umich.edu/icpsrweb/instructors/studies/465
5.

In the final sample used in this paper, there were 581 mothers that ranged in age from 18-68 years old $\left(M_{\mathrm{age}}=38.95\right.$, $S E=.48$ ). Race of respondents were as follows: $81.58 \%$ White/Caucasian, 10.84\% Black/African American, 3.79\% Latina/Hispanic, $0.34 \%$ Asian, 3.44\% Multi-racial/other racial group. These categories were recorded to a binary variable for racial minority status: the White/Caucasian group was retained as "White" (racial majority group) and all of the non-White respondents (racial minority groups) were re-categorized as "Nonwhites."

\begin{tabular}{|c|c|c|c|c|}
\hline & Total & Whites & Nonwhites & $p$ \\
\hline $\mathrm{N}(\%$ of sample $)$ & $\begin{array}{c}581 \\
(100 \%)\end{array}$ & $\begin{array}{c}474 \\
(81.58 \%)\end{array}$ & $\begin{array}{c}107 \\
(18.42 \%)\end{array}$ & \\
\hline Age, mean $(S E)$ & $\begin{array}{l}38.95 \\
(.48)\end{array}$ & $\begin{array}{c}39.39 \\
(.51)\end{array}$ & $\begin{array}{l}37.28 \\
(1.25)\end{array}$ & $n s$ \\
\hline $\begin{array}{l}\text { Household income, } \\
\text { mean }(S E) \\
\text { Income in USD, } \\
\text { percentages }\end{array}$ & $\begin{array}{l}3.48 \\
(.08)\end{array}$ & $3.74(.08)$ & $\begin{array}{l}2.59 \\
(.14)\end{array}$ & .000 \\
\hline 1. $<\$ 20,000, \%$ & $13.21 \%$ & $9.03 \%$ & $27.66 \%$ & \\
\hline 2. $\$ 20,000-\$ 34,999, \%$ & $19.23 \%$ & $17.12 \%$ & $26.72 \%$ & \\
\hline 3. $\$ 35,000-\$ 49,999, \%$ & $17.82 \%$ & $17.69 \%$ & $17.93 \%$ & \\
\hline 4. $\$ 50,000-\$ 74,999, \%$ & $19.61 \%$ & $20.25 \%$ & $17.24 \%$ & \\
\hline 5. $\$ 75,000-\$ 99,999, \%$ & $16.15 \%$ & $18.77 \%$ & $7.47 \%$ & \\
\hline 6. $\$ 100,000+, \%$ & $13.99 \%$ & $17.14 \%$ & $2.98 \%$ & \\
\hline Education, mean $(S E)$ & $\begin{array}{r}2.76 \\
(.05)\end{array}$ & $2.83(.05)$ & $\begin{array}{r}2.51 \\
(.09)\end{array}$ & .000 \\
\hline \multicolumn{4}{|l|}{$\begin{array}{l}\text { Highest Education } \\
\text { Level, percentages }\end{array}$} & \\
\hline $\begin{array}{l}2 . \text { High school } \\
\text { graduate, } \%\end{array}$ & $36.67 \%$ & $33.93 \%$ & $45.92 \%$ & \\
\hline $\begin{array}{l}\text { 3. Completed some } \\
\text { college, } \%\end{array}$ & $24.12 \%$ & $23.78 \%$ & $25.56 \%$ & \\
\hline $\begin{array}{l}\text { 4. College graduate or } \\
\text { higher, } \%\end{array}$ & $30.24 \%$ & $33.69 \%$ & $17.95 \%$ & \\
\hline \multicolumn{5}{|l|}{ Other demographics } \\
\hline Employed, \% & $60.85 \%$ & $61.56 \%$ & $57.61 \%$ & $n s$ \\
\hline Homemaker, \% & $27.33 \%$ & $29.81 \%$ & $18.95 \%$ & .006 \\
\hline Married, \% & $70.86 \%$ & $78.21 \%$ & $44.11 \%$ & .000 \\
\hline $\begin{array}{l}\text { Total children at home } \\
<\text { age } 18 \text {, mean }(S E)\end{array}$ & $\begin{array}{l}1.91 \\
(.05)\end{array}$ & $\begin{array}{l}1.89 \\
(.05)\end{array}$ & $\begin{array}{l}2.01 \\
(.11)\end{array}$ & $n s$ \\
\hline $\begin{array}{l}\text { Respondent is primary } \\
\text { childcare provider, } \%\end{array}$ & $84.59 \%$ & $83.3 \%$ & $90.65 \%$ & $n s$ \\
\hline
\end{tabular}

Measures. The following household demographic characteristics were assessed: education, income, employment status, marital status, number of children living at home, and whether respondent (mother) carried the primary childcare responsibilities (see Table I).

Appraisal of relationship quality. Several questions examined respondents' perceptions of their effectiveness as mothers and their relationships with their own mothers and children. The questions were: "How good a job do you feel you're doing as a mother?"; "Overall, how would you describe your relationship with your (child/children)?"; "Overall, how would you describe your relationship with your mother when you were a child?"; "Overall, how would you describe your relationship with your mother now?" response options for each of these questions were (1= Excellent, $2=$ 
Good, 3= Not so good, 4=Poor).

Emotions and Motherhood. Three questions addressed worry and guilt-emotions commonly associated with motherhood. The questions were: "How much, if at all, do you worry about not being as good a mother as you would like to be?" (1=Great deal, 2=Somewhat, 3= Not so much, 4=Hardly at all, 5=Never/Not at all); "Is not being as good a mother as you would like to be something you ever feel guilty about, or not?" (1=Yes, often, 2=Yes, occasionally, $3=$ No $)$; and "What's the main thing you feel guilty about as a mother?' (open-ended/free response).

Intergenerational Relationships. Respondents' perceptions of their relationships with their own mothers were examined. Questions included: "Thinking about your current relationship with your mother, do you think of yourself more as her (child), or more as her (friend)?"; "Compared to when you were a child, in general do you think being a mother today is (harder), (easier) or about the same?"; "When it comes to discipline and manners, are you (more) strict with your (child/children) than your mother was with you, (less) strict, or about the same?"; "All in all, compared to the way your mother raised you, would you say you're doing a (better) job raising your (child/children), a (worse) job, or about the same?" (1=Much better, 2=Somewhat better, 3=Somewhat worse, 4=Much worse).

\section{RESULTS}

Results adjusted for the following covariates: age, education, income, and number of children under age 18 living at home.

$\mathbf{H}_{1 \mathbf{a}}$ : White and Nonwhite mothers will not differ in how they assess their effectiveness as parents.

Nonwhite mothers expressed less insecurity about their abilities as mothers $(M=1.49, S E=.05)$ than White mothers $(M=1.64, S E=.02)$ before adjusting for covariates $(b=.14$, $\left.S E_{\mathrm{B}}=.06, p=.012\right), F(1,577.86)=6.29, p=.012, R^{2}=.02$. After adjusting for covariates the model improved $F(5$, 536.46)=5.60, $p<.000, R^{2}=.05$ (see Fig. 1).

$\mathbf{H}_{\mathbf{1 b}}$ : White and Nonwhites will differ in their reports of worry, guilt and sources of guilt

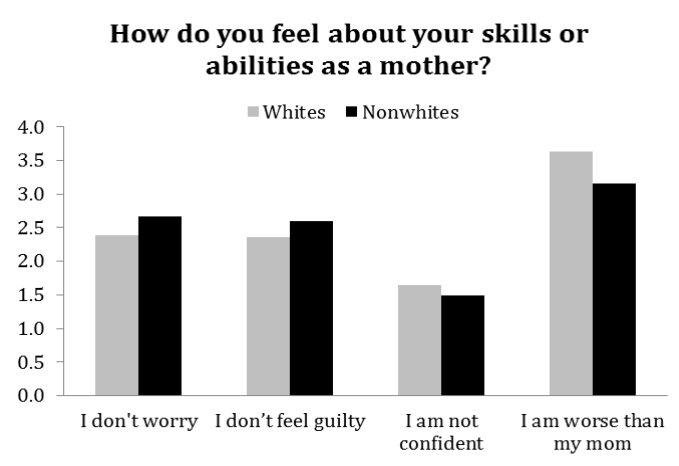

Fig. 1. Respondents' appraisals of their parenting abilities.

White mothers were also less self-assured (more worried) that they could live up to their ideals of being a "good mother" $(M=2.39, S E=.05)$ than Nonwhites $(M=2.66, S E=.14)$. The relationship was marginally significant before adjusting for covariates $\left(b=-.27, S E_{\mathrm{B}}=.15, p=.07\right), \quad F(1,578.05)=3.30$, $p=.06, R^{2}=.01$ and statistically significant after adjusting $(b=$ -.33, $\left.S E_{\mathrm{B}}=.15, p=.026\right), F(5,537.22)=4.76, p<.000, R^{2}=.07$ (see Fig. 1).

Similarly, White mothers expressed more guilt about not being a good enough mother [lower scores indicate more guilt]. White mothers' reports $(M=2.36, S E=.03)$ significantly differed from Nonwhite mothers' $(\mathrm{M}=2.60, \mathrm{SE}=.06),(b=-.24$, $\left.S E_{\mathrm{B}}=.07, p=.001\right), \quad F(1,559.37)=12.15, p=.000, \quad R^{2}=.03$. Adjusting for covariates improved the model $(b=-.27$, $\left.S E_{\mathrm{B}}=.07, p=.000\right), F(5,521.14)=7.05, p<.000, R^{2}=.07$. Among White mothers, the most common causes of guilt were not having enough time for children (41.82\%) and impatience/short temper (11.24\%). The most common causes of guilt for Nonwhite mothers were not having enough time (37.87\%) and lack of money/resources (18.92\%) (see Fig. 2).

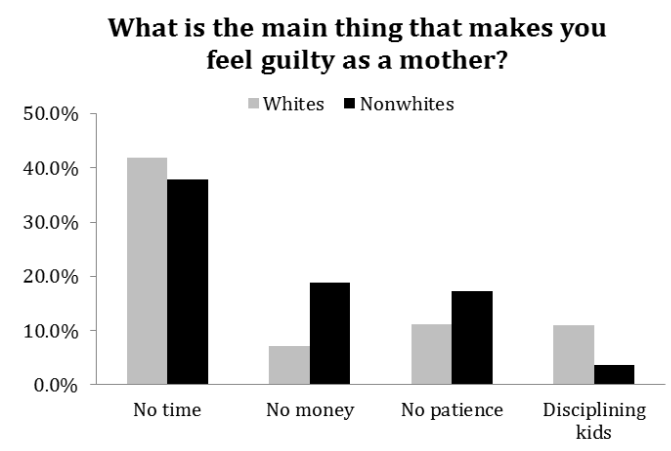

Fig. 2. Sources of respondents' parenting guilt.

$\mathbf{H}_{2 \mathbf{a}}$ : Whites and Nonwhites will differ in their self-reported closeness to their mothers.

Next, intergenerational relationships were examined. White mothers reported better relationships with their own mothers in the past (i.e. during their youth) and in the present. During their youth, White mothers $(M=1.94, S E=.05)$ perceived that their relationships with their own mothers were less strained (better quality) than Nonwhite mothers $(M=2.23$, $S E=.13)\left(b=-.29, S E_{\mathrm{B}}=.14, p=.039\right), F(1,581.15)=4.30$, $p=.039, R^{2}=.01$. Similarly, among respondents whose mothers were alive, White mothers perceived that their current relationships with their aging mothers were presently less strained (better quality) $(M=2.13, S E=.07)$ than Nonwhites $(M=2.50, S E=.17)\left(b=-.36, S E_{\mathrm{B}}=.18, p=.048\right), F(1,570.88)$ $=3.92, p=.048, R^{2}=.01$. When asked about whether they currently think of themselves as mostly a "child" or mostly a "friend" in their relationship with their mother, $53.1 \%$ of Whites perceived that they were "friends" to their mothers while $40.67 \%$ of Nonwhites perceived the same.

$\mathbf{H}_{2 \mathbf{b}}$ : Women that report having closer relationships with their mothers in the past will also report more satisfying relationships with their own children currently.

Analyses revealed that Whites and Nonwhites did not differ in their perceptions of the quality of their relationships with their children before or after adjusting for covariates $F(5$, $537.22)=1.88, n s, R^{2}=.02$. Although minority status did not predict mothers' perceived relationship quality with their children, mothers that reported better quality relationships with their mothers while they were young also reported better quality relationships with their own children before adjusting for covariates $\left(b=.10, S E_{\mathrm{B}}=.02, p<.000\right), F(1,582.48)=20.65$, 
$p<.000, R^{2}=.04$. After adjusting for covariates as well as the presence of teenagers and toddlers (dummy variables), the model was still significant $F(7,539.14)=7.75, p<.000$, $R^{2}=10$.

$\mathbf{H}_{\mathbf{2 c}}$ : Whites will be more likely to emulate their mothers' parenting style

Whites and Nonwhites differed in how much they emulated their mothers' parenting styles during their youth. White mothers most frequently reported that they raised their children with similarly strict parenting styles as their mothers (59\%) while the remainder of Whites indicated that they were less strict $(18.62 \%)$ or more strict $(22.36 \%)$ than their mothers. In contrast, among Nonwhites, only $36.54 \%$ were equally as strict as their mothers, $30.13 \%$ were less strict, and $33.33 \%$ were stricter (see Fig. 3). A Pearson chi-square between the variables (minority status and strictness) was statistically significant, $\chi^{2}=9.10, p=.011$.

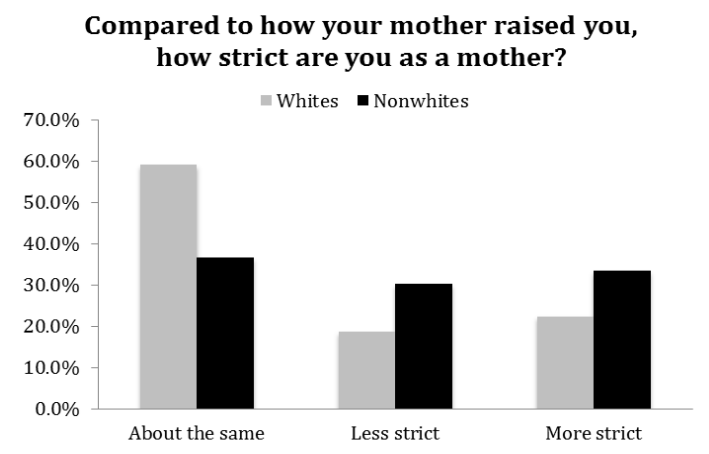

Fig. 3. Respondents' comparisons of intergenerational parenting styles.

Both Whites and Nonwhites believed that being a mother was more difficult in the present day compared to during the historical times that their mothers raised them (70\%). Additionally, Nonwhites $(M=3.16, S E=.21)$ believed that they were less inadequate (more effective) mothers than their own mothers in contrast to Whites $(M=3.63, S E=.09)$ before adjusting for covariates $\left(b=.47, S E_{\mathrm{B}}=.22, p=.036\right), F(1$, $558.31)=4.43, p=.036, R^{2}=.01$ and after adjusting $F(5$, $518.85)=3.59, p=.003, R^{2}=.05$.

\section{CONCLUSION}

Results from this national sample suggested that racial minority status may still play an important role in shaping how women experience and interpret motherhood. Although Whites (majority group) are more socioeconomically privileged and more likely to be married, they were less confident in their parenting abilities and expressed more worry and guilt than Nonwhites. This manifests that stereotypically "disadvantaged" groups (Nonwhites) may have additional social psychological resources that buffer against obstacles to parenting that Whites may lack. Further, the finding that a substantial source of guilt for Nonwhites was lack of money/financial resources underscores the significance of intersections of social status, race and class in mothers' stressful experiences. One advantage for White mothers was that they reported closer relationships with their mothers in the past and present. However, since Whites felt more inadequate compared to their own mothers' effectiveness, they may have been more exposed to (and more pressured to measure up to) an "intensive mothering" standard that contributed to their guilt and feelings of incompetency. Future research should directly explore how women's perception of living in a prejudiced society impacted their experiences of motherhood, and also examine other intersections of inequality (e.g. disability status, immigration status, or sexual orientation).

\section{ACKNOWLEDGMENT}

The author thanks the Center for the Education of Women at the University of Michigan for its financial support during the preparation of this manuscript.

\section{REFERENCES}

[1] United States Census Bureau. Mother's Day. Profile America: Facts for Features 2010. [Online]. Available: https://http://www.census.gov/newsroom/releases/archives/facts_for_f eatures_special_editions/cb12-ff08.html

[2] J. M. Heisler and J. B. Ellis, "Motherhood and the construction of 'Mommy Identity': messages about motherhood and face negotiation," Communication Quarterly, vol. 56, no. 4, pp. 445-467, 2008.

[3] S. Medina and S. Magnuson, "Motherhood in the 21st Century: Implications for counselors," Journal of Counseling and Development, vol. 87, no. 1, pp. 90-96, 2009.

[4] S. Hays, The Cultural Contradictions of Motherhood, 1996, New Haven [Conn.]: Yale University Press, XV, p. 252.

[5] M. Liss, H. Schiffrin, and K. Rizzo, "Maternal guilt and shame: The role of self-discrepancy and fear of negative evaluation," Journal of Child and Family Studies, vol. 22, no. 8, pp. 1112-1119, 2013.

[6] J. A. Sutherland, "Mothering, guilt and shame," Sociology Compass, vol. 4, no. 5, pp. 310-321, 2010.

[7] C. Vincent, S. J. Ball, and S. Pietikainen, "Metropolitan mothers: Mothers, mothering and paid work," Women's Studies International Forum, vol. 27, no. 5-6, pp. 571-587, 2004.

[8] P. Tummala-Narra, "Contemporary Impingements on Mothering," American Journal of Psychoanalysis, vol. 69, no. 1, pp. 4-21, 2009.

[9] J. Belsky, R. Conger, and D. M. Capaldi, "The intergenerational transmission of parenting: Introduction to the special section," Developmental Psychology, vol. 45, no. 5, pp. 1201-1204, 2009.

[10] P. H. Collins, "Shifting the center: Race, class, and feminist theorizing about motherhood," in Mothering: Ideology, Experience, and Agency, E. N. Glenn, G. Chang, and L. R. Forcey, Eds. 1994, Routledge: New York, p. 45-65.

[11] J. Crocker and B. Major, "Social stigma and self-esteem: The self-protective properties of stigma," Psychological Review, vol. 96, no. 4, pp. 608-630, 1989.

[12] L. Y. Zhou, "What college students know about older adults: A cross-cultural qualitative study," Educational Gerontology, vol. 33, no.10, pp. 811-831, 2007.

[13] K. Christopher, "Extensive mothering: Employed mothers' constructions of the good mother," Gender \& Society, vol. 26, no. 1, pp. 73-96, 2012.

[14] S. Elliott, R. Powell, and J. Brenton, "Being a good mom: Low-income, black single mothers negotiate intensive mothering," Journal of Family Issues, vol. 36, no. 3, pp. 351-370, 2015.

[15] A. Lareau, "Invisible Inequality: Social class and childrearing in black families and white families," American Sociological Review, vol. 67, no. 5, pp. 747-776, 2002.

[16] ABC News/Good Housekeeping Mother's Day Poll, January 2006, 2007, Inter-university Consortium for Political and Social Research (ICPSR) [distributor].

Ekeoma E. Uzogara received her $\mathrm{PhD}$ degree in social psychology and master degree in public health at the University of Michigan, Ann Arbor. She is currently a postdoctoral fellow at the Center for the Education of Women at the University of Michigan. Her research is at the interface of social sciences, health, and wellness and has focused on the life experiences of disadvantaged or stigmatized individuals. More recently, she has examined how perceived discrimination, stress, and physical differences such as skin color among ethnic minority populations (e.g. Blacks and Latinos) contribute to economic inequality and health disparities in the $21^{\text {st }}$ century. 